\title{
UM ESTUDO SOBRE O DESEMPENHO FINANCEIRO DO ÍNDICE BOVESPA DE SUSTENTABILIDADE EMPRESARIAL
}

\section{A STUDY ABOUT THE FINANCIAL PERFORMANCE OF BOVESPA ÍNDICE OF ENTERPRISE SUSTAINABILITY}

\section{UN ESTUDIO SOBRE EL DESEMPEÑO FINANCIERO DEL ÍNDICE BOVESPA DE SUSTENTACIÓN EMPRESARIAL}

\begin{abstract}
IDÁLIA ANTUNES CANGUSSÚ REZENDE
Contadora, mestre em Ciências Contábeis com ênfase em Finanças pela Fucape Fundaçao Instituto Capixaba de Pesquisas em Contabilidade, Economia e Finanças. Professora da Faserra e Uniest de graduação e especialização.

idaliaantunes@yahoo.com.br

\section{JULYANA GOLDNER NUNES}

Contadora, especializada em Controladoria e Finanças, mestranda em Contabilidade com ênfase em Finanças pela Fucape - Fundação Instituto Capixaba de Pesquisas em

Contabilidade, Economia e Finanças.

julyanagn@hotmail.com

\section{SIMONE SALLES PORTELA}

Contadora, especializada em Controladoria e Finanças, mestranda em Contabilidade com ênfase em Finanças pela Fucape - Fundação Instituto Capixaba de Pesquisas em

Contabilidade, Economia e Finanças.

simone.portela@gmail.com
\end{abstract}

\section{RESUMO}

Este estudo investiga os investimentos socialmente responsáveis, bem como a sua conceituação e o contexto mundial e brasileiro, a fim de fundamentar a existên- 
cia dos índices de sustentabilidade empresarial. Além disso, buscou-se verificar se o retorno do índice de sustentabilidade empresarial é semelhante aos índices de ações convencionais da Bolsa de Valores de São Paulo (Bovespa). Para tanto, realizou-se uma fundamentação teórica baseada na teoria dos stakeholders ou teoria dos grupos de interesse e na teoria dos shareholdes ou teoria da maximização da riqueza dos acionistas. Essas teorias buscam uma relação entre Responsabilidade Social Corporativa (RSC) e desempenho financeiro das empresas. Esta pesquisa foi desenvolvida a partir de uma revisão bibliográfica, na qual foram realizados testes estatísticos que comparam o retorno médio do Índice Bovespa de Sustentabilidade Empresarial (ISE) com o retorno médio do Índice Bovespa (Ibovespa), Índice Brasil (IBrx) e do Índice de Ações com Governança Corporativa Diferenciada (IGC). As evidências encontradas, por meio da utilização de testes estatísticos, demonstram que apesar de o ISE possuir uma carteira teórica diferenciada, voltada ao tema social, ambiental e ético, o seu retorno é semeIhante aos índices de ações convencionais.

Palavras chave: Índice de Sustentabilidade Empresarial, teoria dos Stakeholders, teoria dos Shareholders.

\section{ABSTRACT}

This study investigates the investments socially responsible, as well as its concept, the brazilian and world landscape, in order to base the existence of the indexes of managerial Sustainability. Besides, it was looked for to verify the return of the index of managerial Sustainability it is similar to the indexes of conventional actions of the stock exchange of São Paulo (BOVESPA).In order to do so, a literature review based on the stakeholder theory or the theory of interest group and the shareholder theory or the theory of shareholders' wealth maximization was carried out. These theories look for a relationship between corporate social responsibility (CSR) and financial performance of companies. This research was developed starting from a bibliographical revision, in that were accomplished statistical tests that compare the medium return of the Index Bovespa of Managerial Sustainability (ISE) with Index Bovespa's medium return (Ibovespa), Index Brasil (IBrx) and of the Index of Actions with Differentiated Corporate Governance (IGC). The found evidences, by means of the use of statistical tests, they demonstrate that in spite of ISE to possess a differentiated theoretical wallet, returned to the social, environmental and ethical theme, its return is similar to the indexes of conventional actions.

Keywords: Sustainability Managerial Index, The Stakeholders Theory, The Shareholders Theory. 


\section{repec}

\section{RESUMEN}

Este estudio investiga las inversiones socialmente responsables, así como su conceptuación y el contexto mundial y brasileño, a fin de fundamentar la existencia de los índices de sustentación empresarial. Además, se buscó verificar si el retorno del índice de sustentación empresarial es semejante a los índices de acciones convencionales de la Bolsa de Sao Paulo (Bovespa). Para ello, se realizó una fundamentación teorética basada en la teoría de los stakeholders o teoría de los grupos de interés y en la teoría de los shareholdes o teoría de la maximización de la riqueza de los accionistas. Esas teorías buscan una relación entre Responsabilidad Social Corporativa (RSC) y desempeño financiero de las empresas. Esta pesquisa fue desarrollada desde una revisión bibliográfica, en la cual fueron realizados testes estadísticos que comparan el retorno medio del Índice Bovespa de Sustentación Empresarial (ISE) con el retorno medio del Índice Bovespa (Ibovespa), Índice Brasil (IBrx) y del Índice de Acciones con Gobierno Corporativa Diferenciada (IGC). Las evidencias encontradas, por medio de la utilización de testes estadísticos, demuestran que a pesar del ISE poseer una cartera teórica diferenciada, dirigida al tema social, ambiental y ético, su retorno es semejante a los índices de acciones convencionales.

Palabras-clave: Índice de Sustentación Empresarial, teoría de los Stakeholders, teoría de los Shareholders.

\section{INTRODUÇÃO}

A adesão das empresas ao desenvolvimento sustentável, que equivale a um compromisso permanente com a integridade do meio ambiente e aos princípios da responsabilidade social, fez com que o mercado financeiro, por meio das instituições financeiras, implementasse mudanças institucionais, como indicadores, ratings e fundos de investimentos socialmente responsáveis.

Os indicadores socioambientais, como é o caso do Índice de Sustentabilidade Empresarial (ISE), criado em 2005 pela Bolsa de Valores de São Paulo; o Índice Dow Jones de Sustentabilidade, instituído em 1999 com intuito de "premiar as empresas que procuram aliar desenvolvimento com eco-eficiência e responsabilidade social" (May et al., 2003, p. 189); e a criação de ratings socioambientais pelas instituições financeiras, que têm o objetivo de avaliar empréstimos e financiamentos, são atos que começam a incorporar os riscos sociais e ambientais no mercado de capitais e de créditos.

O Índice de Sustentabilidade Empresarial (ISE) consiste em um índice de sustentabilidade empresarial nos moldes dos índices Dow Jones Sustainability 
Indexes (DJSI), FTSE4Good Series e Johannesburg Stock Exchange SRI Index e tem como objetivo propiciar um ambiente de investimento compatível com as demandas de desenvolvimento sustentável da sociedade contemporânea e estimular a responsabilidade social corporativa, considerando aspectos de governança corporativa e sustentabilidade empresarial (eficiência econômica, equilíbrio ambiental e justiça social) (Bovespa, 2005).

A preocupação com o meio ambiente mediante um desenvolvimento sustentável, além de outras medidas responsáveis, como responsabilidade social e práticas de governança corporativa, está criando uma demanda dentro do mercado financeiro para produtos voltados a esse nicho.

A sustentabilidade é a capacidade de as empresas aliar sucesso financeiro com atuação social e equilíbrio ambiental. De acordo com Bergamini Júnior (2002),

o relato baseado na sustentabilidade pressupõe ampla transparência das empresas com relação às três linhas principais, representadas pelo desempenho financeiro, pela questão ambiental e pelos aspectos social/ ético/comunitário.

Com o fortalecimento da ótica social nas organizações, surgiram algumas percepções que envolvem a Responsabilidade Social Corporativa (RSC) versus desempenho financeiro. Nesse contexto, emergem algumas alternativas conceituais para explicações administrativas mais amplas, destacando-se a "teoria dos stackeholders" ou a "teoria dos grupos de interesse", que ressalta a importância estratégica de se atender aos interesses dos stackeholders, e sugere uma relação positiva entre RSC e desempenho financeiro das organizações. Para Borba (2005, p. 09), "diversos autores, alinhados ao aspecto instrumental da teoria dos stackholders, entendem que a responsabilidade social das empresas serviria como um meio para o alcance de melhor desempenho financeiro".

Entretanto, a "teoria dos shareholders" ou a "teoria da maximização do valor para o acionista", segundo Borba (2005, p. 6), "[...] ainda é bastante presente e pouco questionada, já que a construção de argumentos teóricos e empíricos contrários a ela ainda precisam ser melhor elaborados e analisados".

Conforme Griffin e Mahon (1997), a partir da década de 70, surgiram diversos estudos empíricos que tentaram sem grande sucesso identificar por meio de ferramentas estatísticas uma relação positiva entre RSC e desempenho financeiro, que confirmaria a eficiência da "teoria dos stackeholders". Entretanto, na maioria desses estudos, para os problemas relacionados à utilização de diversas metodologias, à fragilidade de indicadores de desempenho social corporativa e à indefinição conceitual surgiram conclusões questionáveis e inconsistentes. 
Para Watts e Zimmerman (1978), existem cinco fatores que afetam a riqueza ou a obtenção de lucro das empresas: impostos, regulação, custos políticos, produção de informações e plano de compensação administrativa. Em relação aos custos políticos, os autores mencionam que o setor político tem o poder de transferir riquezas entre vários grupos, sendo que as corporações são vulneráveis a essas redistribuições.

Determinados grupos de eleitores são incentivados por "lobby" para nacionalização, expropriação e regulação de uma corporação. Para conter essas instruções governamentais, a administração das empresas tenta algumas medidas, tais como campanhas de responsabilidade social nos meios de comunicação e escolha de procedimentos contábeis para minimizar lucros relatados e, conseqüentemente, evitar chamar atenção com altos lucros, reduzindo a probabilidade de ações políticas adversas, reduzindo assim, esses custos políticos (Watts; Zimmerman, 1978).

Diante disso, essa pesquisa se justifica pela discussão sobre o tema mercado acionário brasileiro, integrando-o a questões de responsabilidade social corporativa, com foco no índice de sustentabilidade empresarial. Esse índice possui o conceito de Investimento Socialmente Responsável, ou seja, é composto por empresas que possuem políticas relacionadas à preservação do meio ambiente, responsabilidade social e governança corporativa.

Este trabalho buscaenriquecer o debate atual acerca da relação entre responsabilidade social corporativa e desempenho financeiro, por meio da análise econômico-financeira do índice socialmente responsável brasileiro (ISE) e das empresas que os integram, com intuito de entender melhor essa relação.

Os comentários e as afirmações mostram a necessidade de se conhecer o desempenho econômico-financeiro dos índices de ações considerados socialmente responsáveis, representado pelo Índice Bovespa de Sustentabilidade Empresarial (ISE) em relação aos outros índices. Desse modo, esta pesquisa procura investigar, no âmbito do mercado acionário brasileiro, a seguinte questão: o retorno do Índice Bovespa de Sustentabilidade Empresarial é semelhante ao retorno dos demais índices de ações?

Nesse sentido, este trabalho tem por objetivo investigar a relação entre o retorno do ISE em relação ao retorno dos outros índices (Ibovespa, IBrx e IGC).

\section{REFERENCIAL TEÓRICO}

\subsection{Responsabilidade Social Corporativa (RSC) e o desempenho financeiro}

A atividade das empresas possui uma visão ética, complementar às suas visões econômica e legal. A natureza dessa visão econômica é vista sob a "ótica dos shareholders", em que os gestores têm a função-objetivo de maximizar o retorno dos sócios ou dos acionistas da empresa. A outra teoria é argumentada com base na "ótica 
dos stakeholders", na qual que os gestores têm um compromisso ético de respeitar os direitos entre todas as partes interessadas direta e indiretamente pela empresa (Machado Filho; Zylbersztajn, 2003).

Nos últimos anos, clientes, empregados, fornecedores, comunidade, governos e alguns acionistas têm encorajado as empresas a investirem em Responsabilidade Social Corporativa (RSC). Algumas empresas respondem com mais investimentos em RSC; outras empresas resistem com o argumento de que investimentos em RSC são inconsistentes com os esforços de maximização dos lucros dos acionistas (Mcguire; Sundgren; Schneeweis, 1988).

Para Wood (1991, p. 695), "a idéia básica responsabilidade social corporativa é que o negócio e a sociedade são entrelaçados, ao invés de entidades distintas; a sociedade tem certas expectativas para um comportamento empresarial apropriado e com resultados".

Pesquisas que envolvem RSC e desempenho financeiro têm sido baseadas em vários argumentos teóricos da administração moderna, a teoria dos stakeholders, ou dos grupos de interesse, e a teoria dos shareholders, ou da maximização do valor para o acionista.

\subsubsection{Teoria dos Shareholders}

Brealey e Myers (2000) afirmam que o administrador financeiro deve agir em interesse dos proprietários, que têm como objetivo maximizar a sua própria riqueza. A teoria dos shareholders ou a teoria da maximização da riqueza dos acionistas é ligada às teorias de finanças e de economia.

De acordo com Sundaram e Ikpen (2001), essa abordagem é predominante nos últimos 150 anos, sendo que nesse período nenhuma outra se mostrou mais eficiente.

A teoria dos shareholders mostra uma relação negativa entre responsabilidade social e performance financeira e argumenta que o alto nível de responsabilidades resulta em custos adicionais que colocam as empresas em desvantagem econômica em relação a outras empresas que possuem menos ações e práticas de responsabilidade social (Mcguire, Sundgren e Schneeweis, 1988).

Esses pensamentos são fundamentais para os argumentos de Friedman (1970) e outros economistas neoclássicos, que afirmam:

There are few readily measurable economic benefits to socially responsible behavior while there are numerous costs. The cost, by this argument, fall directly to the bottom line, reducing profits and thus shareholder wealth. These theorists expect the relationship between RSP and financial performance to be negative (Waddock; Graves, 1997).

Friedman (1970), ganhador do Prêmio Nobel de Economia em 1976, afirma que a única responsabilidade social da empresa é a de gerar lucros e riqueza para seus acionistas, 
tendo, portanto, como responsabilidade o desempenho econômico, e que qualquer posição diferente dessa irá enfraquecer as empresas e o sistema capitalista.

Em recente entrevista, Milton Friedman, ao ser indagado se a empresa deve ter responsabilidade social, mencionou:

Não. Deve gerar lucro. Se os donos quiserem usar os ativos para atender seus valores de responsabilidade social, tudo bem - afinal, estarão gastando o seu próprio dinheiro. Pode ser vantajoso para uma corporação chamar de responsabilidade social uma ação que, na verdade, visa beneficiar a própria empresa. Aliás, há mais marketing que substância na onda social das empresas (Lahóz, 2005, p. 40).

Friedman (1970, p. 02) argumenta que os gastos com responsabilidade social podem estar adicionando custos aos stakeholders. Em relação a esse aspecto, ele destaca:

A situação do proprietário-indivíduo é um pouco diferente. Se ele agir para reduzir os lucros da empresa com intuito de exercitar a responsabilidade social, ele está gastando o seu próprio dinheiro, não de outros. Se ele deseja gastar seu dinheiro neste propósito, é seu direito, e eu não posso ver que há qualquer objeção para tanto. No processo, ele, também, pode impor custos aos empregados e consumidores (tradução nossa).

Sundaram e Ikpen (2001) evidenciam que ao maximizar o valor do acionista, todo o valor da empresa é maximizado, assim, os stakeholders seriam favorecidos, se a empresa obtivesse sucesso em longo prazo.

\subsubsection{Teoria dos Stakeholders}

A definição de stakeholder mais utilizada foi feita por Freeman (1984, p. 46), que define como "qualquer grupo ou indivíduo que afeta ou é afetado pelo alcance dos objetivos da empresa".

A teoria que trata da relação positiva entre RSC e performance financeira é a teoria dos stakeholder. A sua doutrina baseia-se na idéia de que o resultado final da atividade de uma organização empresarial deve levar em consideração os retornos que otimizam os resultados de todos os stakeholders envolvidos, e não apenas os resultados dos acionistas (Freeman, 1984).

As ações de responsabilidade social com base na teoria dos stakeholders se justificariam, de acordo com Wood (1991, p. 695), pois

a idéia básica da responsabilidade social corporativa é que a atividade de negócios e a sociedade são entidades interligadas e não distintas. Portanto, a sociedade tem certas expectativas em relação ao comportamento e resultados das atividades de negócios (tradução nossa). 
Freeman (1984) afirma que a gestão com base na teoria dos stakeholders envolve a alocação de recursos organizacionais e a consideração dos impactos dessa alocação em vários grupos de interesse dentro e fora da organização. Portanto, a argumentação central da teoria dos stakeholders é a de que os administradores devem também tomar decisões levando em conta os interesses de todos os grupos envolvidos, que são os stakeholders primários (acionistas e credores) e secundários (comunidades, funcionários, fornecedores, entre outros), ou seja, todos os indivíduos ou grupos que, substancialmente, podem afetar ou ser afetados pelas decisões da empresa.

Observa-se então que a teoria dos stakeholders, em seu aspecto instrumental, aproxima-se do conceito de RSC (Carrol, 1979), uma vez que identifica vantagens estratégicas para a adoção de uma administração voltada para os interesses de todos os grupos envolvidos direta e indiretamente nas atividades da empresa.

A teoria dos stakeholders evidencia que a empresa deve assumir múltiplos objetivos e não apenas a função-objetivo de maximização da riqueza do acionista (teoria dos shareholders).

Em relação a essa essência, Jensen (2001) se opõe e aponta erros conceituais nessa ótica e reitera, na mesma linha dos argumentos apresentados por Friedman (1970), a lógica de que a empresa deve seguir apenas uma função-objetivo, que é a busca da maximização do valor de mercado da empresa.

Existem tanto críticas negativas a essa teoria quanto as elaboradas por Jensen (2001) e Sternberg (1999). Essas críticas fundamentam-se, principalmente, na falta de um objetivo principal, com clara conformação à teoria dos shareholders, em que uma única função-objetivo prevalece: a maximização da riqueza dos sócios ou dos acionistas.

Jensen (2001) sustenta que os múltiplos objetivos da "teoria dos stakeholders" são, na verdade, estratégias, e a criação de valor é o principal objetivo a ser seguido como referência pelas empresas. De acordo com o autor, a teoria não possui clareza de uma missão fornecida por um único objetivo corporativo, pois as "companhias que adotam a teoria dos stakeholders acabarão passando por confusão gerencial, conflito, ineficiência e, talvez, fracasso corporativo" (Jesen, 2001, p. 9).

Sternberg (1999) crítica a responsabilidade múltipla atribuída à empresa, que dificulta a existência de objetivos claros e de maior importância, pois cada grupo estabelece suas prioridades e define seus próprios objetivos, ocasionando vários problemas estratégicos para a empresa.

Finalmente, Jensen (2001) conclui que a teoria dos stakeholders seria uma prescrição para destruição de valor da empresa e redução do bem-estar social. Entretanto, o autor não se contrapõe à prática de ações de responsabilidade social por parte das empresas, que podem servir estrategicamente no processo de busca de valor por parte das organizações, pois uma empresa não consegue maximizar seu valor se ignorar os interesses de seus stakeholders, porém, sempre objetivando a maximização do valor da empresa. 
Harrison e Freeman (1999) realizaram um estudo sobre stakeholders, responsabilidade social e performance. Neste trabalho, foram analisadas pesquisas que relacionam a teoria dos stakeholders, responsabilidade social corporativa e performance financeira. Com o intuito de verificaro relacionamento entre os modelos degestão dos stakeholderse a performance financeira da empresa foram desenvolvidos dois modelos. O primeiro chama-se "gestão estratégica dos stakeholders" e o segundo modelo é o "compromisso intrínseco dos stakeholders".

A "gestão estratégica dos stakeholders" reflete uma abordagem instrumental, sugerindo que o interesse dos stakeholders é motivado pela percepção de que a responsabilidade social corporativa pode fornecer performance financeira. O modelo do "compromisso intrínseco dos stakeholders" apóia-se na hipótese de que as empresas têm um compromisso normativo para avançar com os interesses do stakeholder e que esse compromisso forma as estratégias da empresa e influência na performance financeira (Harrison; Freeman, 1999).

Donaldson e Preston (1995) afirmam que existem vários problemas nessas abordagens empíricas, apesar de os estudos que buscam uma possível conexão entre RSC e performance financeira terem seus méritos. A grande maioria desses estudos não inclui indicadores confiáveis relacionados à administração dos stakeholders ou ao desempenho das ações de responsabilidade social corporativa.

Com base nas teorias que relacionam RSC e performance financeira, McWilliams e Siegel (2001) afirmam que os estudos empíricos têm sido inconclusivos, resultando relações neutras, positivas e negativas.

Wood (1991) afirma que tal casualidade é complexa, pois a relação entre desempenho social e performance financeira é ambígua, pois não existe uma medida de desempenho social corporativo.

Conforme Freeman e McVea (2000), os resultados encontrados até a presente data são apenas tentativas, pois as técnicas e as fontes de dados ainda estão sendo desenvolvidas.

Na mesma linha de pensamento, Jones e Murrell (2001) dizem que a relação entre práticas de responsabilidade social e desempenho econômico-financeiro é inconclusiva, porque, de acordo com o contexto, poderão existir correlações positivas e negativas entre o investimento em ações de responsabilidade social e o desempenho financeiro. Esse tipo de correlação é motivo de discussão em diversos estudos acadêmicos, mas com resultados contraditórios.

\subsection{Revisão de literatura sobre o desempenho dos Investimentos Socialmente Responsáveis (SRI)}

O maior questionamento nos estudos de desempenho dos investimentos socialmente responsáveis é se esses investimentos possuem desempenho melhor, pior ou semelhante 
aos outros investimentos convencionais, que não utilizam os critérios sociais, ambientais e de governança corporativa como seleção dos melhores papéis.

De acordo com Bauer, Derwall e Otten (2003, p. 03) "Initial ethical fund studies primarily focused on traditional performance methods, such as the Sharpe or Jensen measure, to compare ethical mutual funds to either conventional mutual funds or an ethical or standard index".

Statman (2000) investigou o desempenho de 31 fundos SRI americanos e o Domini Social Index (DSI), um índice que compõe ações de empresas socialmente responsáveis, criado em maio de 1990 pela Kinder, Lydenberg, Domini \& Company (KLD) e composto por 400 empresas. A pesquisa foi realizada nos períodos de maio de 1990 a setembro de 1998, que demonstra que, apesar de o Alfa de Jensen ser positivo para os fundos SRI e para o índice SRI (DSI), a performance é semelhante aos índices e fundos convencionais.

Plantinga e Scholtens (2001), em pesquisa realizada entre 1994 e 1999 com mais de 800 fundos de investimentos europeus da Bélgica, da França e da Holanda, concluíram que os fundos de investimento socialmente responsáveis tendem para uma melhor performance (risco versus retorno) do que os fundos que não têm relação com estratégias de investimento socialmente responsáveis. Utilizaram como metodologia de cálculo o Índice de Sharpe.

Garz, Volk e Gilles (2002) investigaram dois índices da Bolsa de Valores de Nova Iorque, o Índice Dow Jones de Sustentabilidade (DJSI) e o Índice Dow Jones STOXX (DJTOXX), sendo que este considera critérios convencionais para a sua composição. Por meio do Alfa de Jensen, e considerando o modelo de três fatores (retorno em excesso do índice DJTOXX, a medida de exposição ao risco no que se refere à avaliação da empresa e o tamanho das empresas), a pesquisa mostra que o índice DJSI possui um alfa positivo e conclui que o desempenho não é pior do que o índice DJTOXX, encontrando sinais de melhor performance.

Schröder (2004) utilizou o Índice Sharpe para medir o desempenho de 30 fundos de investimento socialmente responsáveis dos Estados Unidos e 16 fundos da Alemanha e Suíça. Verificou que os fundos de investimentos socialmente responsáveis possuem performance similar aos seus benchmarks. Os resultados da análise de desempenho mostram que os fundos SRI alemães e suíços possuem em sua carteira empresas menores, enquanto que os americanos possuem mais investimentos em ações blue chips, ou seja, ações de empresas tradicionais e de grande porte, com grande liquidez e procura no mercado de ações. Além dessa característica que pode influenciar no desempenho desses fundos, o estudo mostra os fatores macroeconômicos, como taxa de juros, produção industrial e variação da moeda. Todavia, conclui que os índices e os fundos SRI possuem algumas características específicas na relação risco-retorno, que pode ser caracterizado como investimentos especiais, diferentes dos ativos convencionais. 
Derwall e Koedjjk (2005) demonstraram que os fundos SRI de renda fixa possuem desempenho estável nos períodos de 1987 a 2003, mas que, apesar disso, a média da performance dos fundos SRI é semelhante aos fundos convencionais. Para esse estudo, foram utilizados diversos modelos de avaliação de performance, tais como Índice de Sharpe, Alfa de Jensen, além da análise estatística de regressões.

Barnett e Salomon (2002) afirmam que o crescimento de pesquisas empíricas tem suportado posições contraditórias na relação entre performance social e performance financeira dos Investimentos Socialmente Responsáveis (SRI), e os resultados dos estudos têm sido mistos. Verificou-se ainda que os fundos do tipo Screening, que excluem da carteira empresas de setores, como fumo, álcool, pornografia, jogos de azar, material bélico e energia nuclear, influenciam nos resultados quando são comparados com fundos não screening. A maioria dos estudos não tem contado com esses critérios sociais heterogêneos de formação dos fundos SRI, pois, além do tipo Screening, existem os fundos SRI dos tipos Shareholder Advocacy e Community Investiment.

Assim, observa-se que os estudos realizados sobre desempenho financeiro de investimentos socialmente responsáveis apresentam vários resultados, que, em sua maioria, indicam evidências de desempenho semelhante, mas que ainda apresentam fragilidades e inconsistências.

\subsection{Investimentos Socialmente Responsáveis: conceituação}

Os investimentos socialmente responsáveis (SRI) são representados por fundos de investimentos, ratings e índices no mercado financeiro.

De acordo com Skillius e Wennberg (1998), o fenômeno do investimento socialmente responsável surgiu em 1920, quando certas instituições evitaram investimentos em empresas ligadas com álcool ou tabaco. Os investimentos que usam critérios ambientais são uma prática mais recente. Fundos que usam esses critérios apareceram por volta de 1970 e 1980. Em 1990, houve um estrondo no número de fundos ambientais.

Os investimentos socialmente responsáveis são decisões de investimento com o objetivo duplo de atingir retorno financeiro e social. Segundo Ferreira (2004, p. 237) o seu crescimento "reforça a relação entre a responsabilidade social e a valorização dos papéis da empresa".

O mercado acionário tem buscado alternativas de aplicações em fundos que tragam a minimização do risco e a maximização do retorno aos acionistas e aos investidores, com diferentes perfis. Um exemplo são os investimentos socialmente responsáveis, que surgiram da necessidade de se encontrar alternativas de investimento que atendessem a investidores que estivessem buscando aplicações diferenciadas no mercado e a premiar as empresas que aliam desenvolvimento sustentável, responsabilidade social e práticas de governança corporativa. 


\section{repec}

As empresas cumprem sua tarefa perante o governo e a sociedade, pagando impostos, gerando empregos e adotando práticas de responsabilidade social com padrões éticos para estabelecer os termos de relacionamento com a comunidade na qual estão instaladas. Por isso, os fundos que investem em empresas dessa natureza também são chamados de fundos éticos.

Os SRIs são investimentos efetuados por empresas e investidores preocupados com as questões éticas, sociais e ambientais, com os objetivos de obter retorno financeiro e retorno indireto, como a sua relação com o mercado financeiro e a adequação às políticas socioambientais das instituições financeiras.

Os fundos de investimento em ações de empresas que têm estratégia competitiva de responsabilidade social, ética e ambiental são um novo segmento da indústria de fundos mútuos em renda variável e, atualmente, representam um segmento promissor em países do mundo, como os Estados Unidos e o Japão, além de alguns países da Europa e da América Latina.

No cenário mundial, com destaque para os Estados Unidos, os Socially Responsible Funds existem há mais de duas décadas. Esses investimentos são baseados não apenas nos riscos financeiros das empresas, mas também nos riscos sociais e ambientais e já representam cerca de $13 \%$ do total investido. De acordo com Furtado $(2003$, p. 01), os fundos SRI constituem 230 fundos múltiplos nos EUA,

que utilizam algumas das chamadas screenings, ou peneiras, cuja função é identificar nas corporações com ações negociadas alguma característica não-desejável nos aspectos ambientais ou sociais [...] O fundo do tipo screening é o mais comum e tem como princípio negociar apenas ações de empresas com boa conduta social, ambiental e de relação trabalhista, excluindo da carteira companhias de setores malvistos: fumo, álcool, pornografia, jogos de azar, material bélico e energia nuclear (grifo nosso).

De acordo com Larson (2003, p. 6), "o fenômeno de acionistas usarem sua influência para influenciar as práticas de responsabilidade social dos negócios é relativamente novo". Em conseqüência desse fenômeno, as empresas têm definido ações mais responsáveis, pois os grupos de acionistas ativistas têm influenciado no comportamento das companhias.

Também em relação aos critérios de seleção dos papéis, os investimentos socialmente responsáveis têm uma larga gama de práticas e indicadores em relação aos critérios de inclusão. Villani (2005), gestor dos Fundos Ethical, destaca que

as empresas são avaliadas pelo conjunto de suas práticas em relação a condições de trabalho, poluição de ar, da água e do solo, eficiência ecológica, respeito a clientes, ações sociais e comunitárias, direitos dos acionistas minoritários, efetividade do conselho de administração, além de vários outros indicadores. 
Com relação ao Brasil, o Índice Bovespa de Sustentabilidade Empresarial (ISE) foi lançado em novembro de 2005 e realizou-se uma revisão em dezembro de 2006 de seus parâmetros para assegurar a correta aferição do nível de sustentabilidade empresarial das empresas listadas na bolsa.

Não há exclusão de setores econômicos ISE, como no modelo do tipo screening dos fundos de investimento socialmente responsáveis americanos e brasileiros. O ISE é do tipo positive screening, ou seja, não há exclusão por princípio de nenhum setor. Dessa forma, todas as empresas com liquidez mínima no mercado poderão preencher o questionário e participar da seleção. Todos os elementos associados à sustentabilidade de cada setor serão avaliados, incluindo riscos potenciais e impactos adversos associados à natureza dos produtos e serviços de cada empresa (Bovespa, 2005).

O conceito do ISE é o do triple bottom line, com base na consultoria inglesa SustainAbility, que avalia elementos econômico-financeiros, sociais e ambientais de forma integrada. A esses princípios foram acrescentados critérios e indicadores de governança corporativa, seguindo o modelo do índice da Bolsa de Johannesburg, o que deu origem a um quarto grupo temático (Bovespa, 2005).

Os quatro blocos são precedidos por um grupo de indicadores gerais básicos e de natureza do produto. Entre esses indicadores gerais e de natureza do produto incluemse: publicação do Balanço Social ou de Sustentabilidade; se houve endosso ao Pacto Global da Organização das Nações Unidas (ONU); e se o consumo ou a utilização dos produtos da companhia acarretam danos efetivos ou riscos à saúde, à integridade física ou à segurança dos consumidores, de terceiros, ou ainda relacionados à saúde e à segurança públicas.

\section{METODOLOGIA}

\subsection{Formulação das hipóteses}

Sob a ótica da teoria dos shareholders, o papel principal das empresas é gerar lucros aos seus sócios ou acionistas (Friedman, 1970; Sundaram e Ilpen, 2001; Brealey e Myers, 2000; Jensen 2001) e as visões conflitantes da teoria dos stakeholders (Freeman, 1984, Drucker, 1993) mostra as empresas atendendo às necessidades dos principais stakeholders, ou grupos de interesse, melhorando sua reputação de tal forma que houvesse um impacto positivo na performance financeira.

De acordo com a teoria dos shareholders, refletida pela posição de Friedman (1970), o envolvimento da empresa em ações de RSC levaria a gastos desnecessários, resultando em custos adicionais e desvantagem competitiva em relação à concorrência que não pratica essas ações sociais. Desse modo, a relação entre RSC e performance financeira seria negativa. 


\section{repec}

Entretanto, as evidências empíricas das teorias dos shareholders e dos stakeholders são inconsistentes e questionáveis. Por isso, a hipótese principal é a de que o desempenho econômico-financeiro dos investimentos socialmente responsáveis é semelhante aos investimentos convencionais.

Sendo assim, a hipótese apresentada inicialmente indica retorno semelhante, ou seja, a relação entre RSC e desempenho financeiro do Índice Bovespa de Sustentabilidade Empresarial (ISE) não difere dos outros índices de ações, por terem critérios de seleção baseados em questões ambientais, sociais e éticas. A principal hipótese investigativa que objetiva responder ao problema principal é:

\section{$\mathrm{H}_{0}$ : $\mathrm{O}$ Índice Bovespa de Sustentabilidade Empresarial possui retorno semelhante aos demais índices de ações.}

\subsection{Coleta de dados}

Os dados sobre o Índice Bovespa de Sustentabilidade Empresarial (ISE), o Índice Bovespa (Ibovespa), o Índice Brasil (IBrx) e o Índice de Ações com Governança Corporativa Diferenciada (IGC) foram obtidos por meio do banco de dados disponibilizados pelo Economática.

O motivo dessa escolha é que os índices de ações Ibovespa, IBrx e IGC possuem outros critérios de seleção de melhores papéis. O IBrX é um índice de preços que mede o retorno de uma carteira teórica composta por 100 ações selecionadas entre as mais negociadas na Bovespa em termos de número de negócios e volume financeiro. O IGC tem por objetivo medir o desempenho de uma carteira teórica composta por ações de empresas que apresentem bons níveis de governança corporativa, negociadas nos Níveis 1 ou 2 e Novo Mercado.

O lbovespa é o indicador do desempenho médio das cotações do mercado de ações brasileiro. O Índice Bovespa é um índice da Bolsa de Valores de São Paulo (Bovespa) que mede a lucratividade de uma carteira hipotética das ações mais negociadas na Bovespa. Cada ação integrante da carteira recebe um peso que varia de acordo com sua liquidez. Representam $80 \%$ do volume transacionado à vista nos doze meses anteriores à formação da carteira e, para que a sua representatividade se mantenha ao longo do tempo, é feita uma reavaliação quadrimestral.

Com a necessidade de se obter dados históricos sobre o retorno mensal dos índices de ações, a amostra é representada por quatro índices de ações constituídos e em funcionamento de dezembro de 2005 a março de 2007, considerando que é a data de lançamento do ISE.

Com o intuito de testar a hipótese atribuída a essa pesquisa, as variáveis escolhidas para análise foram os retornos mensais do ISE, Ibovespa, IBrx e IGC. 


\section{ANÁLISE E INTERPRETAÇÃO DOS DADOS}

\subsection{Estatística descritiva dos Índices de Ações}

Conforme apresentado na Tabela 1, o retorno mensal do Índice Bovespa de Sustentabilidade Empresarial (ISE) médio foi de 0,023, sendo 0,090 o menor retorno do grupo e 0,182 o maior, com desvio padrão de 0,0612 , em torno da média.

Tabela 1: Estatística Descritiva da Variável Retorno Mensal do ISE

\begin{tabular}{l|l|l|l|l|l|l|l}
\hline & $\mathbf{n}$ & Mínimo & Média & Mediana & Máximo & $\begin{array}{l}\text { Desvio } \\
\text { Padrão }\end{array}$ & $\begin{array}{l}\text { Variância } \\
\text { da amostra }\end{array}$ \\
\hline $\begin{array}{l}\text { Retorno } \\
\text { mensal }\end{array}$ & 16 & $-0,09031733$ & 0,02320528 & 0,02583801 & 0,18269231 & 0,06127942 & 0,00375517 \\
\hline
\end{tabular}

$\mathrm{Na}$ Tabela 2, o retorno mensal do Índice Bovespa (Ibovespa) médio foi de 0,024, sendo 0,095 o menor retorno do grupo e 0,147 o maior, com desvio padrão de 0,054, em torno da média.

Tabela 2: Estatística Descritiva da Variável Retorno Mensal do lbovespa

\begin{tabular}{l|l|l|l|l|l|l|l}
\hline & $\mathrm{n}$ & Mínimo & Média & Mediana & Máximo & $\begin{array}{l}\text { Desvio } \\
\text { Padrão }\end{array}$ & $\begin{array}{l}\text { Variância da } \\
\text { amostra }\end{array}$ \\
\hline $\begin{array}{r}\text { Retorno } \\
\text { mensal }\end{array}$ & 16 & $-0,09498563$ & 0,02417148 & 0,00912378 & 0,14706673 & 0,05483024 & 0,00300636 \\
\hline
\end{tabular}

A terceira variável analisada é o retorno mensal médio do Índice Brasil (IBrx), conforme apresentado na Tabela 3. O retorno do IBrx médio foi de 0,025 , sendo 0,074 o menor retorno do grupo e 0,183 o maior, com desvio padrão de 0,059 , em torno da média.

Tabela 3: Estatística Descritiva da Variável Retorno Mensal do IBrx

\begin{tabular}{l|l|l|l|l|l|l|l}
\hline & $\mathbf{n}$ & Mínimo & Média & Mediana & Máximo & $\begin{array}{l}\text { Desvio } \\
\text { Padrão }\end{array}$ & $\begin{array}{l}\text { Variância da } \\
\text { amostra }\end{array}$ \\
\hline $\begin{array}{c}\text { Retorno } \\
\text { mensal }\end{array}$ & 16 & $-0,0747059$ & 0,02565107 & 0,01304497 & 0,18302362 & 0,05966318 & 0,05966318 \\
\hline
\end{tabular}

A variável retorno mensal médio do Índice de Ações com Governança Corporativa Diferenciada (IGC), conforme apresentado na Tabela 4, foi de 0,028 , sendo 0,068 o menor retorno do grupo e 0,179 o maior, com desvio padrão de 0,055 , em torno da média. 
Tabela 4: Estatística Descritiva da Variável Retorno Mensal do IGC

\begin{tabular}{c|c|c|c|c|c|c|c}
\hline & $\mathbf{N}$ & Mínimo & Média & Mediana & Máximo & $\begin{array}{c}\text { Desvio } \\
\text { Padrão }\end{array}$ & $\begin{array}{c}\text { Variância da } \\
\text { amostra }\end{array}$ \\
\hline $\begin{array}{c}\text { Retorno } \\
\text { mensal }\end{array}$ & 16 & $-0,06868131$ & 0,028179049 & 0,01495763 & 0,179234973 & 0,055050618 & 0,003030571 \\
\hline
\end{tabular}

\subsection{Testes de Hipótese ( $t)$ : duas amostras para média}

De acordo com Stevenson (1986, p. 223) o Teste-T: Duas Amostras para Médias "consiste em verificar se uma estatística amostral observada pode razoavelmente provir de uma população com o parâmetro alegado".

A seguir, são demonstrados oito testes de hipótese para diferenciação de duas médias aritméticas, com intuito de:

a. Comparar as médias do retorno mensal do ISE com a do Ibovespa;

b. Comparar as médias do retorno mensal do ISE com a do IBrx;

c. Comparar as médias do retorno mensal do ISE com a do IGC.

Com o objetivo de se avaliar se a média dos retornos de 16 meses do ISE pertencentes a $\mu_{I S E}$ é estatisticamente semelhante a ${ }^{\mu_{\text {IBOVESPA }}}$, pertencentes ao lbovespa, aplicou-se o teste de hipótese $(\mathrm{t})$ para duas amostras.

Assim, admitindo-se o nível de significância do teste de hipótese $\alpha$, igual a 0,05, estabeleceram-se duas hipóteses:

$$
\begin{aligned}
& H_{0}: \mu_{I S E}=\mu_{\text {IBOVESPA }} \\
& H_{1}: \mu_{I S E} \neq \mu_{\text {IBOVESPA }}
\end{aligned}
$$

Onde,

$\mu_{I S E}$ representa a média dos retornos mensais do ISE;

$\mu_{\text {IBOVESPA }}$ representa a média dos retornos mensais do lbovespa.

\section{Tabela 5: Teste de Hipótese para a Variável Retorno Mensal Ibovespa}

\begin{tabular}{c|c|c|c|c}
\hline $\begin{array}{c}\text { Média do retorno } \\
\text { mensal do ISE } \\
\mu_{I S E}\end{array}$ & $\begin{array}{c}\text { Média do retorno mensal } \\
\text { do Ibovespa } \\
\mu_{I B O V E S P A}\end{array}$ & $\begin{array}{c}\text { Estatística de } \\
\text { teste (t) }\end{array}$ & p-value & Resultado \\
\hline 0,02320528 & 0,02417148 & $-0,04700072$ & 0,9628241 & Não rejeitar H0 \\
\hline
\end{tabular}

Ao se observar a Tabela 5 que o $p$-value ou $\mathrm{P}(\mathrm{T}<=\mathrm{t})$ bi-caudal é igual a 0,96 , na estatística do teste (t), é maior que o nível de significância a igual a 0,05. Portanto. a decisão é de não rejeitar $\mathrm{HO}$, ou seja, a média dos retornos mensais referentes ao ISE ( $\mu_{I S E}$ ) não é estatisticamente diferente da média dos retornos mensais do lbovespa ( $\left.\mu_{\text {IBOVESPA }}\right)$. 
Com o intuito de se avaliar se a média dos retornos de 16 meses do ISE pertencentes a $\mu_{I S E}$ é estatisticamente semelhante a ${ }^{\mu_{I B x x}}$, pertencentes ao IBrx, aplicou-se o teste de hipótese (t) para duas amostras.

Dessa forma, admitindo-se o nível de significância, do teste de hipótese a, igual a 0,05, estabeleceram-se duas hipóteses:

$H_{0}: \mu_{I S E}=\mu_{I B r x}$
$H_{1}: \mu_{I S E} \neq \mu_{I B r x}$

Onde,

$\mu_{I S E}$ representa a média dos retornos mensais do ISE;

$\mu_{I B r s}$ representa a média dos retornos mensais do Ibrx.

Tabela 6: Teste de Hipótese para a Variável Retorno Mensal IBrX

\begin{tabular}{c|c|c|c|c}
\hline $\begin{array}{c}\text { Média do retorno } \\
\text { mensal do ISE } \\
\mu_{I S E}\end{array}$ & $\begin{array}{c}\text { Média do retorno } \\
\text { mensal do IBrX } \\
\mu_{I B r}\end{array}$ & $\begin{array}{c}\text { Estatística de } \\
\text { teste (t) }\end{array}$ & p-value & Resultado \\
\hline 0,02320528 & 0,0256510 & $-0,11438675$ & 0,90969335 & Não rejeitar H0 \\
\hline
\end{tabular}

Observando-se a Tabela 6 que o $p$-value ou $\mathrm{P}(\mathrm{T}<=\mathrm{t})$ bi-caudal é igual a 0,91, na estatística do teste (t), é maior que o nível de significância a igual a 0,05. Portanto. a decisão é de não rejeitar $\mathrm{HO}$, ou seja, a média dos retornos mensais referentes ao ISE ( ${ }^{\mu_{I S E}}$ ) não é estatisticamente diferente da média dos retornos mensais do IBrx ( $\mu \mathrm{IBrx}$ ).

Com objetivo de se avaliar se a média dos retornos de 16 meses do ISE pertencentes a $\mu_{I S E}$ é estatisticamente semelhante a ${ }^{\mu_{I G C}}$, pertencentes ao IGC, aplicou-se o teste de hipótese (t) para duas amostras.

Dessa forma, admitindo-se o nível de significância, do teste de hipótese a, igual a 0,05, estabeleceram-se duas hipóteses:

$H_{0}: \mu_{I S E}=\mu_{I G C}$

$H_{1}: \mu_{I S E} \neq \mu_{I G C}$

Onde,

$\mu_{I S E}$ representa a média dos retornos mensais do ISE;

$\mu_{I G C}$ representa a média dos retornos mensais do IGC.

Tabela 7: Teste de Hipótese para a Variável Retorno Mensal IGC

\begin{tabular}{c|c|c|c|c}
\hline $\begin{array}{c}\text { Média do retorno } \\
\text { mensal do ISE } \\
\mu_{I S E}\end{array}$ & $\begin{array}{c}\text { Média do retorno } \\
\text { mensal do IBrX } \\
\mu_{I G C}\end{array}$ & $\begin{array}{c}\text { Estatística de } \\
\text { teste }(\mathbf{t})\end{array}$ & p-value & Resultado \\
\hline 0,02320528 & 0,02817905 & $-0,241516563$ & 0,8107980 & Não rejeitar H0 \\
\hline
\end{tabular}


Conforme representado na Tabela 7 que o p-value ou $\mathrm{P}(\mathrm{T}<=\mathrm{t})$ bi-caudal é igual a 0,81 , na estatística do teste $(\mathrm{t})$, é maior que o nível de significância a igual a 0,05 . Portanto, a decisão é de não rejeitar $\mathrm{H} 0$, ou seja, a média dos retornos mensais referentes ao ISE ( $\mu_{I S E}$ ) não é estatisticamente diferente da média dos retornos mensais do IGC ( $\left.\mu_{I G C}\right)$.

Os principais resultados demonstrados por meio da estatística descritiva, referente ao retorno médio dos 16 meses - dezembro de 2005 a março de 2007 do ISE $(0,023)$, do Ibovespa $(0,024)$, do $\operatorname{IBrx}(0,025)$ e do IGC $(0,028)$ proporcionam evidências que tornam possível a confirmação da hipótese do trabalho.

Para avaliar essa afirmação, sobre as médias dos retornos mensais, foi realizado o Teste T: de duas amostras para média. Ao comparar o ISE versus Ibovespa, o ISE versus IBrx e o ISE versus IGC, por meio do Teste T, pode-se confirmar a hipótese de que o retorno médio do índice de sustentabilidade empresarial é estatisticamente igual ao dos demais índices de ações.

Dessa forma, todos os testes empíricos realizados nessa pesquisa indicam que o retorno do ISE é semelhante aos retornos dos outros índices de ações.

\section{CONCLUSÕES}

Esta pesquisa analisou a relação entre o retorno do ISE em relação ao retorno dos outros índices (Ibovespa, IBrx e IGC).

Os resultados originados pelo teste empírico realizado nesta pesquisa geraram um conjunto de evidências que ampliam a discussão sobre a relação entre retorno financeiro e investimentos socialmente responsáveis. Entretanto, é importante ressaltar que as evidências encontradas e discutidas nesta pesquisa devem ser consideradas respeitando-se os limites da metodologia aplicada e da amostra utilizada.

As evidências encontradas permitem algumas conclusões, de acordo com a questão inicialmente lançada.

Os resultados originados pelas investigações empíricas, por meio do Teste-T, confirmaram a hipótese principal levantada neste trabalho de que o índice de sustentabilidade empresarial possui retorno semelhante aos outros índices de ações.

O índice de sustentabilidade empresarial não possui melhor retorno que outros índices de ações, por selecionarem empresas considerando o conceito de sustentabilidade empresarial, que considera o crescimento econômico, a eqüidade social e o equilíbrio ecológico como premissas para benefícios financeiros e vantagens competitivas.

Apesar dos resultados obtidos e das conclusões apresentadas, deve-se levar em consideração a limitação da pesquisa referente ao tamanho do período de estudo (16 meses) para os índices de ações. Essa utilização ocorreu devido à necessidade de se trabalhar com uma base de dados homogênea e pelo fato de que o ISE surgiu no Brasil em novembro de 2005. 
De acordo com as relações identificadas nesta pesquisa, bem como nas conclusões e na limitação apresentada, sugere-se, para o desenvolvimento de novas pesquisas:

- realizar estudos, da mesma natureza, usando outros critérios de seleção para investimentos socialmente responsáveis, como fundos de investimento socialmente responsáveis;

- ampliar o número de meses nos testes empíricos, considerando a disponibilidade dos dados com o passar do tempo.

- sugerir, para novas pesquisas, testes empíricos que demonstrem comparações entre o retorno e o desempenho (risco versus retorno) das empresas que integram as carteiras teóricas dos índices de ações (ISE, Ibovespa, IBrx e IGC) (o Índice Bovespa de Sustentabilidade Empresarial possui em sua carteira teórica empresas comuns aos outros índices de ações).

- verificar a influência de outras características e/ou variáveis (nível de liquidez, tamanho das empresas, setor, dentre outras) sobre a relação entre retorno financeiro e empresas consideradas socialmente responsáveis;

Por fim, espera-se que as evidências encontradas nesta pesquisa contribuam para aumentar o conhecimento sobre os investimentos socialmente responsáveis.

\section{REFERÊNCIAS}

BARNETT, Michael L.; SALOMON, Robert M. Unpacking social responsibility: the curvilinear relationship between social and financial performance. Academy of management Proceedings, 2002. Disponível em http://papers.ssrn.com/sol3/papers.cfm?abstract_ $\mathrm{id}=624124$. Acesso em: $1^{\circ}$ abr. 2006.

BAUER, R.; KOEDIJK K.; OTTEN R. International evidence on ethical mutual fund performance and investment style. Journal of Banking and Finance, Forthcoming, 2002. Disponível em: <http://papers.ssrn.com/sol3/papers.cfm?abstract_id=873601>. Acesso em: 20 jan. 2006.

BAUER, Rob; DERWALL, Jeroen; OTTEN, Roger. Canadian ethical mutual funds: performance and investment style analysis in a multifactor framework. Limburg Institute of Financial Economics Working Paper n. 03-001, 2003. Disponível em: <http://www. fdewb.unimaas.nl/finance/workingpapers>. Acesso em: 28 mar. 2006.

BERGAMINI JÚNIOR, Sebastião. Contabilidade e riscos ambientais. Disponível em: <http:// www.ida.org.br/artigos/contambiental.pdf>. Acesso em: 05 abr. 2006. 
BORBA, Paulo da Rocha Teixeira. Relação entre desempenho social corporativo e desempenho financeiro de empresas no Brasil. 2005. 135 f. Dissertação (Mestrado em Administração) - Faculdade de Economia, Administração e Contabilidade, Universidade de São Paulo, São Paulo, 2005.

BOVESPA. Mercado: Ações - Índices - Índice de Sustentabilidade Empresarial - ISE. 2005. Disponível em: < http://www.bovespa.com.br>. Acesso em: 01 abr. 2006.

BREALEY, Richard A.; MYERS, Stewart C. Principles of corporate finance. $6^{\mathrm{a}}$. Ed. Boston: The Irwin/McGraw-Hill, 2000.

CARROL, Archie. A three-dimensional conceptual model of corporate performance. Academy of Management Review. Vol. 4, n. 4, p. 497-505, out. 1979.

DERWALL, Jeroen; KOEDIJK, Kees. Socially responsible fixed-income funds. 2005. Disponível em: <http://papers.ssrn.com/sol3/papers.cfm?abstract_id=653881>. Acesso em: 21 abril 2007.

DIBARTOLOMEO, D.; KURTZ L. Managing risk exposures of socially screened portfolios. Northfield Information Services. Boston, 1999. Disponível em: <http:// www. northinfo.com>. Acesso em: 10 jan. 2005.

DONALDSON, Thomas; PRESTON, Lee E. The stakeholder theory of the corporation: concepts, evidence and implications. Academy of Management Review. Ada, vol. 20, n. 1, p. 65-91, 1995.

DRUCKER, Peter Ferdinand. Sociedade pós-capitalista. São Paulo: Pioneira: 1993.

DUARTE JÚNIOR, Marcos Antônio. Análise da performance de investimentos. Disponível em: <http:www.risktech.com.br/PDFs/ANAPERFO.pdf>. Acesso em: 15 mar. 2005.

FERREIRA, Roberto do Nascimento. Responsabilidade social, governança corporativa e valor das empresas. Disponível em: <http://dae2.ufla.br/revista/>. Acesso em: 05 jan. 2005.

FOCO: Fundos "éticos" ganham mais espaço. Disponível em: <http www1.folha.uol. com.br/folha/ especial/2004/containvestimento/ - 10k - 12 fev. 2005 >. Acesso em: 10 abr. 2006. 
FREEMAN, R. Edward. The politics of stakeholders theory: some future directions. In: DIENHART, John W. Business Ethics Quarterly. V. 4, n.4, p. 409-422, 1984.

FRIEDMAN, Milton. Capitalismo e liberdade. 2. ed. São Paulo: Nova Cultura, 1985.

FRIEDMAN, Milton. The Social Responsibility of Business is Increase Its Profits. New York Magazine. New York, n. 33, p. 122-126, set. 1970.

FURTADO, Marcelo. Análise financeira passa a considerar indicador ambiental. Disponível em: <http://www.quimica.com.br/revista/qd411/ambiente.htm>. Acesso em: 10 abr. 2006.

GARZ, Hendrick; VOLK, Cláudia; GILLES, Martin. More gain than pain - SRI: Sustainability Pays Off. 2002. Disponível em: <http://indexes.dowjones.com/mdsidx/downloads/SRI_Empirical_1102_e.pdf>. Acesso em: 20 abr. 2006.

GREGORY, A.; MATATKO J.; LUTHER R. Ethical unit trust financial performance: small company effects and fund size effects. Journal of Business Finance \& Accounting. n. 24, p. 705-725, 1997.

GRIFFIN, Jennifer J.; MAHON, Jonh. The corporate social performance and corporate financial performance debate: twenty-five years of incomparable research. Business and Society. Chicago, v. 36, n. 1, p. 5-31, mar. 1997.

HAMILTON, S., JO H.; STATMAN M. Doing well while doing good? The investment performance of socially responsible mutual funds. Financial Analysts Journal. , p. 62-66, nov./dec. 1993.

HARRISON, Jeffrey; FREEMAN, Edward R. Stakeholders, social resposability, and performance: empirical evidence and theoretical perpectives. Academy of Management Review. Vol. 42, n. 5, p. 479-485, out. 1999.

JENSEN, Michael C. Value maximization, stakeholder theory, and the corporate objective function. Journal of Applied Corporate Finance. Vol. 14, n. 3, p. 8-21, 2001.

KREANDER, N.; GRAY R. H., POWER D. M.; SINCLAIR C. D. Evaluating the performance of ethical and non-ethical funds: a matched pair analysis. Journal of Business Finance \& Accounting. Vol. 32, No. 7-8, p. 1465-1493, 2000. 
LAHÓZ, André. Empresa é para lucrar. Revista Exame. São Paulo: p. 30, mar. 2005.

LARSON, Andrea. Screening investments of stakeholders: socially responsible investing in the United States. University of Virginia - Darden Graduate School of Business Administration, 2003. Disponível em: <http://papers.ssrn.com/sol3/papers.cfm?abstract_ id=909027>. Acesso em: 22 mar. 2006.

LUTHER, R., J; MATATKO D.; CORNER C.. The investment performance of UK "ethical" unit trusts. Accounting Auditing \& Accountability Journal. N. 5, p. 57-70. 1992.

MACHADO FILHO, Cláudio Antonio Pinheiro; ZYLBERSZTAJN, Décio. Responsabilidade social corporativa e a criação de valor para as organizações. Working paper n. 03, 2003. Disponível em: <http://:www.ead.fea.usp.br/wpapers/>. Acesso em: 12 abr. 2007.

MAY, Peter; LUSTOSA, Marília C.; VINHA, Valéria. Economia do meio ambiente: teoria e prática. Rio de Janeiro: Campus, 2003.

MCGUIRE, Jean B.; SUNDGREN, Alison; SCHNEEWEIS, Thomas. Corporate social responsibility and financial performance. Academy of Management Journal. Vol. 31, n. 4, p. 854-872, 1988.

MCWILLIAMS, Abagail; SIEGEL, Donald. Corporate social responsibility and financial performance: correlation or misspecification? Strategic Mangement Journal. Vol. 21, n. 5, p. 603-609, 2000.

PLANTINGA, Auke; SCHOLTENS, Bert. Socially responsible investing and management style of mutual funds in the euronext stock markets. 2001. Disponível em: <http:// papers.ssrn.com/sol3/papers.cfm?abstract_id=259238>. Acesso em: 20 abr. 2007.

SAUER, D. A. The impact of social-responsibility screens on investment performance: evidence from the Domini 400 social index and Domini equity fund. Review of Financial Economics. n. 6, p. 23-35, 1997.

SCHRÖDER, Michael. Is there a difference? The performance characteristics of SRI equity indexes. ZEW Discussion Paper n. 05-50, 2005. Disponível em: <http://papers. ssrn.com/sol3/papers.cfm?abstract_id=774787>. Acesso em: 20 jun. 2006.

SCHRÖDER, Michael. The performance of socially responsible investments: investment funds and indices. Financial markets and portfolio management . Vol. 18, n. 2, p. 122-142, 2004. 
SKILLIUS, Asa; WENNBERG, Ulrika. Continuity, credibility and comparability: key challenges for corporate environmental performance measurement and communication. The International Institute for Industrial Environmental Economics at Lund University, february, 1998. Disponível em: <http://www2.bren.ucsb.edu/ delmas/courses/esm210/ SKILLIUS\%20AND\%20WENNBERGT.pdf>. Acesso em: 20 abr. 2007.

STATMAN, Meir. Socially responsible mutual funds. Association for Investment Management and Research, 2000. Disponível em: < http://lsb.scu.edu/finance/faculty/Statman/articles/sri.corrected.pdf>. Acesso em: 20 abr. 2006.

STERNBERG, Elaine. The stockholder concept: a mistake doctrine. Foundation for Business Responsibility. Leeds, issue paper, n. 4, nov. 1999. Disponível em: < http:// papers.ssrn.com/sol3/papers.cfm?abstract_id=263144>. Acesso em: 15 abr. 2007.

SUNDARAM, Anat K.; INKPEN, Andrew C. The Corporate Objective Revisited. Thunderbird School of Management Working Paper, out. 2001. Disponivel em: < http://papers.ssrn.com/sol3/papers.cfm?abstract_id=293219>. Acesso em: 12 abr. 2007.

VILLANI, Pedro Angeli. Fundo de investimento "ético" tende a crescer no País. Disponível em: <http:// www.aefinanceiro.com.br/artigos/2005/jan/03/212.htm>. Acesso em: 29 mar. 2007.

WADDOCK, Sandra A.; GRAVES, Graves B. The corporate social performance-financial performance link. Strategic Management Journal. Vol. 18, n. 18, p. 309-319, 1997.

WATTS, Ross L; ZIMMERMAM, Jerold L. Towards a positive theory of the determination of accounting standards. The Accounting Review. Vol. 53, n. 1, p. 112-134, jan. 1978.

WHITE, M. A. The performance of environmental mutual funds in the United States and Germany: is there economic hope for "green" investors? Research in Corporate Social Performance and Policy. Supplement 1, p. 323- 344, 1995.

WOOD, Donna J. Corporate social performance revisited. Academy of Management Review. Vol. 16, n. 4, p. 691-718, out. 1991. 